\title{
A Darwinian Approach to Postmodern Critical Theory: Or, How Did Bad Ideas Colonise the Academy?
}

\begin{abstract}
Alan Davison
Many otherwise canny humanists and social scientists would now think it boorish and intolerant to care about whether the ideas they invoke have received any corroboration, since only a soulless positivist would want to pass judgement on a theory before seeing what illuminating effects its application can provoke. A trial of sensibility is the only precaution needed: the theory will have demonstrated its cogency if it brings out meaning and coherence in a given text or problem. Of course, such bogus experiments succeed every time. All they prove is that any thematic stencil will make its own pattern stand out. ${ }^{1}$
\end{abstract}

Frederick Crews

Cultural transmission enables humans to produce ever more adaptive fits to local circumstances. But much in culture is biologically maladaptive. That which makes culture useful - high fidelity transmission - also makes it dangerous. The special biases and capacities that enable us to inhabit our cognitive niche, also allow for the transmission of false and inefficient beliefs and practices that are themselves replicators. ${ }^{2}$

Joseph Bulbulia

\begin{abstract}
This paper proposes a Darwinian approach to examine the persistence and resilience of a peculiar set of misbeliefs that have flourished in intellectual circles over the last several decades. These misbeliefs, such as the prevailing antirational explanatory models within postmodern critical theory (PMCT), might be expected to perish under the weight of critical scrutiny; that is, selection pressures would tend to weed them out in a highly competitive and rigorous "marketplace of ideas" such as the academy. Given the flourishing of PMCT and its attendant communities of practice, political economies, tribalism and social signalling, it is suggested here that it should be approached in a new way: as a significant socio-cultural cluster of misbeliefs worthy of explanation with tools honed via evolutionary science. For example, the prominence of religious-like performativity and self-validating arguments associated with PMCT makes it suitable for study from perspectives such as
\end{abstract}

\footnotetext{
A. Davison

Faculty of Arts and Social Sciences, University of Technology Sydney, P.O Box 123, Broadway NSW 2007, Australia

e-mail: alan.davison@uts.edu.au

${ }^{1}$ Frederick Crews 1986: 173.

2 Joseph Bulbulia 2008: 79.
} 
memetics, evolutionary psychology (EP) and signalling theory, and Moral Foundations Theory (MFT). With these approaches, a hypothesis-driven research agenda could be developed to examine the deeply-rooted cognitive basis and adaptive socio-cultural drivers behind the spread of PMCT. It is proposed that formal and systematic programmes be established to research the phenomenon, and that - just as with the study of religion - we move beyond the now long-established emphasis on intellectual critique and instead establish a broad programme in the Evolutionary Studies of Postmodernism (ESPM).

\section{Keywords}

Adaptive $\cdot$ Evolutionary $\cdot$ Meme $\cdot$ Misbelief $\cdot$ Postmodernism $\cdot$ Signalling $\cdot$ Theory

\section{Introduction}

This paper proposes that we consider adopting a Darwinian, or evolutionary-science based, approach to understanding the flourishing of postmodern critical theory (PMCT). What follows is aimed at those scholars who find the core claims and epistemological foundations of PMCT to be critically flawed and incoherent, yet are curious of its success and intellectual currency. Critiques of PMCT from at least the 1990s were arguably comprehensive in exposing the paucity of evidence and self-contradictions of the more extreme social constructivist claims around science (or scientific approaches) and its methods. ${ }^{3}$ Despite this, many of the underlying ideas of postmodernist theory have flourished and demonstrated surprising resilience to critique. At first glance this is especially puzzling within the niche of academia, where the much-touted "marketplace of ideas" approach should lead to the abandonment (or at least more circumspect use) of such misbeliefs. ${ }^{4}$ Rephrased from the perspective of cultural evolutionary adaptation: shouldn't we expect a survival-of-the-fittest selection process of only the best ideas, due to them withstanding the scrutiny and testing of our vaunted scholarly apparatus? The underlying premise here is that the very success of misbeliefs - whether derived from postmodernism or other movements - is interesting in itself and invites further inquiry as to the resilience of the ideas, and into the growth in those that purport to believe them. Given the longevity of PMCT we are in the position to see it as a "natural experiment of history", as Michael Shermer (2001) might say,

\footnotetext{
${ }^{3}$ Some major texts include: Gross \& Levitt (1994) 1997; Koertge 1998; Sokal \& Bricmont 1998; Hacking \& Hacking 1999; Slingerland 2008; Sokal 2010. There are, of course, many more articles and commentaries that address these same threads. Of the major texts listed two are especially noteworthy: the collections of essays in Koertge (1998), while dated, are exemplary in their nuance and careful case-study examples; while Slingerland (2008) articulates and then links the flaws in postmodernism to its negative impact on science-humanities interdisciplinarity and consilience. A significant forthcoming contribution is Helen Pluckrose \& James Lindsay's 2020 Cynical Theories: How Activist Scholarship Has Made Everything About Race, Gender, and Identity - And Why this Harms Everybody, Pitchstone.

4 "A belief is a functional state of an organism that implements or embodies that organism's endorsement of a particular state of affairs as actual. A misbelief, then, is a belief that to some degree departs from actuality - that is, it is a functional state endorsing a particular state of affairs that happens not to obtain." McKay \& Dennett 2009: 493.
} 
and so can examine its spread and success in the laboratory of the real world by using an evolutionary approach.

The powerful explanatory capacity of a cultural evolutionary approach offers the prospect of shedding light on a multitude of facets of PMCT, and - perhaps most interestingly highlighting the links between the "content" of the ideas and the way in which this sits within a positive feedback loop to the socio-cultural manifestations, such as in- and outgroup behaviours, institutionalisation and the political economy of PMCT programmes.

The essential features of PMCT can be described in various ways, but the recent attempt by Connor Wood (2018) has been cited elsewhere and captures what I consider key:

Knowledge and truth are largely socially constructed, not objectively discovered. What we believe to be "true" is in large part a function of social power: who wields it, who's oppressed by it, how it influences which messages we hear. Power is generally oppressive and self-interested (and implicitly zero-sum). Thus, most claims about supposedly objective truth are actually power plays, or strategies for legitimizing particular social arrangements.

If one aspect lies at the heart of the above, it is - as Edward Slingerland (2007: 78) identifies - "a model of humans as fundamentally linguistic-cultural beings, combined with the belief that our experience of the world is therefore mediated by language or culture all the way down." (Emphasis original.)

Just to be clear on my own position vis-à-vis the sociology of knowledge and scientific/empiricist method generally, I find the following points expressed by the renowned philosopher Philip Kitcher (1998: 36) uncontroversial:

Science is done by human beings, that is, by cognitively limited beings who live in social groups with complicated structures and long histories.

No scientist ever comes to the laboratory or the field without categories and preconceptions that have been shaped by the prior history of the group to which he or she belongs.

The social structures present within science affect the ways in which research is transmitted and received, and this can have an impact on intratheoretical debates. The social structures in which science is embedded affect the kinds of questions that are taken to be most significant and, sometimes, the answers that are proposed and accepted.

Given these underlying positions and perspectives, this paper challenges assumptions of those who hold similar views of PMCT might tend to fall back on and - as a consequence not see the same need for taking the approach proposed here. These assumptions are: 
1. That because PMCT is often internally incoherent and externally weaklyevidenced (or even demonstrably incorrect), it therefore somehow constitutes a "fragile" belief system (rather than possibly an adaptive cluster of ideas);

2. That PMCT is only worth critiquing in order to reject the (albeit paradoxical) claims to "truth" that are made about the world (rather than being an object of study like any other cluster of misbeliefs that might shed light on the human condition); and

3. That the internal weaknesses and lack of external validity will eventually lead to PMCT's demise - i.e. misbeliefs in general will fade as natural selection picks the best ideas to prevail due to inevitable adaptive pressures (as opposed to persisting and showing resilience).

In what follows I draw from Darwinian approaches to problematise each of these assumptions, and encourage novel approaches to comprehending the success and likely longevity of PMCT in the academy and beyond.

\section{Patterns, Errors and Overlapping Paradigms}

Through positing omnipresent but often invisible (at least to all but those equipped to see) power structures, PMCT makes itself a very likely candidate for overzealous "patternicity"; that is, seeing apparent connections and making incorrect assumptions about causes in the patterns observed in the world around us. There are very good evolutionary reasons for humans to believe all patterns are real, that is, to assume - as Michael Shermer (2011) puts it - that all rustles in the grass are due to dangerous predators and not random acts of the wind. Put in a more technical way, we tend to make Type l errors, or see false positives, because most of the time it is better to be wrong about a potentially lethal risk than pontificate and get eaten. This makes perfect Darwinian sense, for as Shermer (2011: 60) explains:

This is the basis for the evolution of all forms of patternicity, including superstition and magical thinking. There was a natural selection for the cognitive process of assuming that all patterns are real and that all patternicities represent real and important phenomena. We are the descendants of the primates who most successfully employed patternicity.

The potential risk with PMCT will be that in seeking signs of oppression, symbolic violence, microaggressions and various other manifestations of hidden power structures, they may be especially liable to Type I errors. Intriguingly, this seems related to the tell-tale "unmasking style" in social theory that has been expressly singled out for criticism by Peter Baehr (2019) in his book of the same name, although for rather different reasons to those presented here.

Compounding the enthusiasm for revealing putative causes and patterns is the widespread and curious lack of interest in developing robust tools to test said patterns or seek alternative explanations, and the frictionless retreat with little cost (reputational or 
otherwise) when facing overwhelming evidential challenges to false claims. If, for example, there are forces lurking behind patterns in the observable world, why not develop rigorous testable hypotheses to engage in these real-world manifestations and weigh them up against alternative explanations? There is, after all, no need to indulge in the convenient sleight-of-paradigm of non-overlapping magisteria (NOMA) here, ${ }^{5}$ as we are all talking about real-world phenomenon with alleged real causes. Even at this point PMCT seems more like a scientifically posing "alternative medicine" lurking within humanities and social sciences, rather than an aesthetic or view of the world removed from such mundane things as gravity and cholesterol. That is, PMCT posits real things with real consequences, but arguably falters at the point of testable hypotheses and welcoming competing models from other domains. How this unhealthy disinterest in competing and more rigorous explanations might have developed and flourished, especially in the academy, is also partly the subject of the remaining sections.

What follows is a more focussed outline of some possible approaches to understanding PMCT, each highlighting a specific discipline or subdiscipline of an evolutionary-based approach. It is hardly comprehensive and no doubt other lines of inquiry will emerge. The goal is to invite further discussion and to encourage those with deep knowledge to design hypothesis-driven studies that can evaluate their potential.

\section{Misbeliefs and Memetics}

The term "misbelief" should not imply that the ideas and practices that collectively make up this cluster maladaptive or bring no benefit. Having said that, McKay and Dennett (2009: 494) pose the underlying puzzle of misbeliefs clearly:

If evolution has designed us to appraise the world accurately and to form true beliefs, how are we to account for the routine exceptions to this rule - instances of misbelief? Most of us at times believe propositions that end up being disproved; many of us produce beliefs that others consider obviously false to begin with; and some of us form beliefs that are not just manifestly but bizarrely false. How can this be? Are all these misbeliefs just accidents, instances of pathology or breakdown, or at best undesirable (but tolerable) by-products? Might some of them, contra the default presumption, be adaptive in and of themselves?

So, benefits may result, or misbeliefs might just be exploiting some cognitive weakness in us, but they are "adaptive" in their own terms (as per memes, below). According to sociologists Boudry and Hofhuis (2018: 162), misbeliefs "are complex and cumulative cultural adaptations that exploit our cognitive foibles in ingenious and unpredictable ways, which cannot be simply read off of human psychology." Indeed, misbeliefs such as PMCT

\footnotetext{
${ }^{5}$ NOMA proposes that religion and science are separate domains, including in the questions they address and the evidence they use. Articulated by Stephen Jay Gould in an essay in Natural History (March 1997: 16-22, and later reprinted in his 1999 book Rock of Ages: Science and Religion in the Fullness of Life, Ballantine.
} 
could even be considered as "evolutionarily fit" in the sense that they possess qualities that tend to benefit their replication and spread, as well as leading to behaviours that reinforce their very adoption.

The survival and flourishing of an idea or cluster of ideas, especially within the context of academia for instance, naturally leads to assumptions regarding the "fitness" of those ideas. I would like to tease this out a little, especially as it relates to PMCT. Perhaps, for example, there are characteristics shared by PMCT and (at least some) pseudosciences that suggest that far from being weak because of their internal or external incoherence or lack of clear evidence, they actually gain strength from these very characteristics? In their study of the epistemic rationale of self-validating belief systems, Boudry and Braeckman (2012) challenge "the common assumption that pseudosciences and other weird belief systems are inherently fragile." Quite the reverse, in fact, for these systems (Boudry and Braeckman 2012: 359):

exhibit a surprising degree of resilience in the face of apparently adverse evidence and criticism from outsiders. Based on a number of findings in cognitive psychology, we argued that this invulnerability of belief systems may in part explain their unabating popularity. All other things being equal, belief systems that allow the believer to remain outside the reach of refutations, or that provide some convenient ways of coping with difficulties, will be more likely to be selected among competing beliefs and belief systems, and more likely to be disseminated.

That stated, can we understand the phenomenon of PMCT in terms of our evolved psychology? This would be where a "central premise ... is that there is a universal human nature, but that this universality exists primarily at the level of evolved psychological mechanisms, not of expressed cultural behaviours." ${ }^{6}$ Could, in other words, PMCT and its apparent denial of underlying human nature be itself a manifestation of underlying human psychology that is finding a peculiar cultural manifestation today?

With this in mind we can turn to memetics. Memetics is an approach to describing the content and transmission of cultural units; an analogue to the gene. Coined and defined by Richard Dawkins, he introduced the concept in a typically striking passage in The Selfish Gene ([1976] 2006: 192):

I think that a new kind of replicator has recently emerged on this very planet. It is staring us in the face. It is still in its infancy, still drifting clumsily about in its primeval soup, but already it is achieving evolutionary change at a rate that leaves the old gene panting far behind.

The new soup is the soup of human culture. We need a name for the new replicator, a noun that conveys the idea of a unit of cultural transmission, or a unit of imitation. "Mimeme" comes from a suitable Greek root, but I want a monosyllable that sounds

\footnotetext{
${ }^{6}$ Cosmides, Tooby, \& Barko, "Introduction: Evolutionary psychology and conceptual integration," in Barkow, Cosmides \& Tooby 1992: 5.
} 
a bit like "gene". I hope my classicist friends will forgive me if I abbreviate mimeme to meme. If it is any consolation, it could alternatively be thought of as being related to "memory", or to the French word même.

Memetics (or parallel approaches to understanding the transmission of culture) offer some interesting perspectives on PMCT. Rather than focus on the idea of the singular "meme", I will focus on two memetic concepts that I feel have immediate utility; meme-complexes or "memeplexes", and the "meme's-eye" view. ${ }^{7}$ Both concepts invite an examination of the make-up/content of a meme (or meme cluster: "memeplex") from the perspective of cultural adaptation and how these might relate to human cognition and biases.

The meme's-eye view invites us to consider how the content of an idea (or cluster of ideas) might work in regards to its success and dissemination. So, for example, a particular idea might include the proposition that anyone who disagreed with it only serves as evidence of its truth. Applying a meme's eye view to PMCT leads to considering how misbeliefs "[a]re remarkably resilient in the face of counterevidence, as well as displaying certain design features that ensure spurious confirmations" that is, they "seem to exhibit adaptive design ... equipped with immunizing strategies and defense mechanisms which protect them from critical scrutiny and refutation, and they have features that make them self-perpetuating." 8 Thinking of aggregates of such memes encourages us to consider how memeplexes "reinforce in complexes ... so that a suitable existing framework in the mind of the host is especially susceptible to a new meme which fits the framework." ${ }^{9}$

However, it is worth considering that memes that are factually untrue may still serve a common good and positive function, adaptively speaking. Examples could include those memes that enable or enforce strong moral prescriptions that have long-term group stabilising functions. Lahti and Weinstein (2005: 58) present precisely this hypothesis and provide the example of moral rules where "the air of absolutism surrounding moral rules has been maintained in human culture because it buffers the changes in attitude and behavior that would be engendered by stability-dependent cooperation." Moreover, and importantly for what follows, they postulate that (2005: 58) "because all behaviors take time and effort, and therefore have an opportunity cost, memes that are not beneficial are expected to be short-lived. When cultural elements are widespread and persistent, they are likely to have become so because they tended to benefit their bearers." However, memes may be both untrue (misbeliefs) and also serve no positive long-term social function. Unlike moral rules, of course, it's hard to see how systems of thought that make flawed and misleading propositions about the actual world around us (and indeed, "us") can contribute

\footnotetext{
${ }^{7}$ Some other key memetic concepts might apply well to mapping or categorising how PMCT has spread through institutions and social media: vector, replication, transmission and the like.

${ }^{8}$ Boudry \& Braeckman 2012: 162-3.

${ }^{9}$ Finkelstein 2008: 16
} 
to something like long-term social stability: they may flourish and be truly maladaptive to their host animals, but nonetheless thrive due to their "selfishness" or due to their exploitation of deep cognitive attributes.

With some key adaptive aspects identified, can we scrutinize PMCT, especially as it manifests within the peculiar environs of the institutionalised academy, from these same vantage points? More specifically, can we apply with any utility a list of suggested features from "parasitic memes", such as:

Self-justification means that the components of a memeplex mutually justify each other, but without independent support ...

Self-reinforcement means that a meme stimulates its host to rehearse itself, e.g. by repeated study, meditation or prayer...

Intolerance means that a meme indoctrinates its host to a priori reject any competing memes.

Proselytism occurs when a meme promises its carriers a reward if they only accept and spread the meme...

Baiting occurs when a meme promises its carriers a reward if they only accept and spread the meme. ${ }^{10}$

In what ways might PMCT display elements that invite comparisons with "selfish" memes, or perhaps be viewed as part of larger memeplexes that work along the lines outlined above, with its high moralising (e.g. "call-out-culture"), cultivation of group and individual guilt, conventionalism (sacred texts and orthodoxies), and moral tribalism. Critics of PMCT have long noted that it exhibits a number of features which serve to deflect criticism, evade critical tests and engender spurious confirmation, as well as leverage essentialised guilt. These mechanisms bear a striking resemblance to strategies used in classical pseudosciences and other irrational belief systems. From this position, studies utilising perspectives from evolutionary science that have looked into extreme religious practices, pseudoscience, conspiracy theory beliefs and various other forms of misbelief suggest themselves to be well-suited to examine PMCT. ${ }^{11}$

\section{Signalling Theory}

Several commentators and scholars such as Peter Boghossian, James Lindsay, Mike Nayna and Clay Routledge amongst many others, have drawn attention to the religious-like qualities of the campus social justice activism, rooted as it is in postmodernism. ${ }^{12}$ Boghossian and Lindsay pinpoint what they see as connection over sin, in that:

\footnotetext{
${ }^{10}$ From Heylighen \& Chielens 2009: 3217.

${ }^{11}$ Some hot topics that might attract analysis from the perspective of a meme's eye view could include: "blank-slate"-ism \& social determinism; biological sex and gender; the link between terrorism and belief systems; and "white fragility".

${ }^{12}$ For example: James Lindsay and Peter Boghossian's "Privilege: The Left's Original Sin" (quoted in "Is 'privilege like Original Sin"', https://whyevolutionistrue.wordpress.com/2016/05/24/is-privilegelike-original-sin/, originally posted May 24 2016); Boghossian and Mike Nayna, "Postmodern Religion
} 
For many contemporary left-situated activists, privilege occupies the same role in a religion of contemporary identity politics. There is no greater sin than having been born an able-bodied, straight, white male who identifies as a man but isn't deeply sorry for this utterly unintentional state of affairs. ${ }^{13}$

Clay Routledge (2017) considers that activism on campus "fits the profile of being a religious surrogate," and that Postmodernism "has many quasi-religious psychological qualities. Postmodernists prioritize subjective feelings and personal testimonies over objective reality." ${ }^{14}$ Aside from the nature or motivation behind these beliefs, however, Routledge has concerns on how Postmodernism is signalled and performed within the context of academia, for here he sees that it "has characteristics in common with religious fundamentalism. ... ideas cannot be questioned and anyone who challenges far-left dogma is viewed as a blasphemer or apostate. And like in any fundamentalist group, blasphemers and apostates are threatened with punishment or are socially ostracized." ${ }^{15}$ Can various approaches to understanding religious beliefs and practices from an evolutionary perspective be of use in explaining the content of PMCT or the cluster of behaviours that tend to accompany it?

Cognitive science of religion (CSR) is a new and rapidly emerging discipline that "attempts to explain causally the recurrence or religious beliefs and practices, and the role they play in social and political arrangements by appealing to the underlying mental structures and dynamics that make people generally receptive to certain ideas and actions." ${ }^{16}$ It is closely aligned with, but somewhat distinct from the evolutionary studies - especially evolutionary psychology (EP) - of religion, in that it focusses upon mental structures rather than the reasons these structures may have developed as such. ${ }^{17}$

For the purposes of applying insights from both fields to $\mathrm{PMCT}$, one particularly promising line of inquiry utilized by CSR scholars is signalling theory. Signalling theory examines the way in which organisms communicate, especially with an eye to the evolutionary context of the costs and benefits of any adaptation necessary for the act of signalling (think Peacock's tail). ${ }^{18}$ Signalling theory is especially interesting when applied to visible or prominent attention-seeking behaviour in complex socio-cultural contexts, and its potential for understanding contemporary institutional and social media-driven behaviours looks

and the Faith of Social Justice", Areo, December 18, 2018.

https://areomagazine.com/2018/12/18/postmodern-religion-and-the-faith-of-social-justice/

${ }^{13}$ Lindsay and Boghossian, "Privilege: The Left's Original Sin."

${ }^{14}$ Malhar Mali, "On Human Motivation, Ideological Bias, and Groupthink in Academia - An Interview with Clay Routledge", Areo, 23 May 2017. https://areomagazine.com/2017/05/23/on-humanmotivation-ideological-bias-and-groupthink-in-academia-an-interview-with-clay-routledge/

${ }^{15}$ Routledge, "On Human Motivation".

${ }^{16}$ Barrett 2013: 409.

17 Barrett 2013: 410.

${ }^{18}$ Shaver \& Bulbulia 2017: 103. 
intriguing. In recent years there has been a series of interesting evolutionary theory based hypotheses and models seeking to explain not only some aspects of the content of religions, but - more importantly for the current argument - also the attendant behaviours and rituals that go with them. ${ }^{19}$ Explanatory models based upon "honest" and "charismatic" signalling, niche-construction and religious ecologies are promising in their possible application to PMCT and the behaviours of communities of practice associated with it.

The avoidance of rigorous tests and the high moralising element, combined with the apparent compartmentalism of PMCT vis-à-vis our reliance upon the "truth" of sciencebased knowledge, suggests strong parallels with the cognitive and adaptive systems of fundamentalist religion may be at play here. Bulbulia (2008: 97) points out that, assuming that religious commitment is a false belief (misbelief) and that the widespread belief in $\operatorname{god}(s)$ is not the cause of that belief, it follows that "religious information needs to be managed so that it does not come into contact with core practical domains outside cooperative contexts [e.g. such as within a religious ceremony or ritual]." Hence the allergic reaction to hypothesis-driven tests or engagement with accepted norms of evidence.

Pursuing the parallels further, central to the compartmentalisation and avoidance of testing in the real world is "niche-construction" (see Bulbulia 2008) and the broader ecology supporting religious beliefs which are to be understood as highly-adaptive in their own way. Niche construction refers to the way in which organisms can change the conditions within which selection processes work - an example of the interaction between culture and genetics if you will. Bulbulia (2008: 87) characterises a "religious niche" as

A system of organized behavior and knowledge, together with whatever artifacts and other symbolic structures ... that are supported, retained, improved, and transmitted at least in part because we possess the cognitive capacities to believe and morally commit to supernatural realities and purposes. ... Whatever its psychological basis, the religious niche reduces social complexity by strengthening and disambiguating signals of co-operation.

So, perhaps PMCT is also highly adaptive in that in order to facilitate its continued existence within the academy it has normalised a culture of eschewing rigorous tests and critiques, while at the same time reinforcing and ritualising (through signalling) various practices that solidify co-operation and compartmetalism.

\footnotetext{
${ }^{19}$ Some recent promising scholarship has looked th the importance of signalling within religious contexts, highlighting its adaptive costs and benefits. As described by Shaver and Bulbulia (2016: 104):

The prevalence of religion across cultures and throughout human history suggests that religion is a product of evolutionary dynamics. Signaling theorists hypothesize that religious systems evolve to facilitate within-group cooperation because religious costs enable partners to reliably predict the cooperation of others".
} 
Aside from signalling as a way of indicating membership to a group and its associated behaviours/values, an intriguing concept that turns this unidirectional relationship on its head is "charismatic signalling" theory. Charismatic signalling is a model that seeks to understand the mechanisms by which large-scale co-operative behaviours are caused by certain categories of signalling, rather than the usual signalling showing membership or conformity to a group/expectation. According to Bulbulia \& Sosis (2011: 376) charismatic display "... is configured to cause [cooperative] traits in others," especially so in others where there is no personal contact or communication. This model of charismatic ecologies may apply well to virtual communities tightly connected through social media, or to interconnected institutions such as universities where there are dominant socio-political viewpoints meshed with belief systems that encourage visible group identity.

\section{Moral Foundations Theory}

Moral Foundations Theory (MFT) is most famously associated with the social psychologist Jonathan Haidt, whose book The Righteous Mind (2012) greatly popularised a theory of moral psychology. Jesse Graham, Haidt and others crystalized their MFT in a 2013 paper where they outlined their theory based upon the evolutionary assumption that "the human mind is organised in advance of experience so that it is prepared to learn values, norms, and behaviors, to a diverse set of recurrent adaptive social problems" or, nicely expressed another way: "there is a first draft of the moral mind organized in advance of experience by the adaptive pressure of our unique evolutionary history." 20

The actual moral foundations proposed by the theory comprise of an initial (by no means comprehensive) set of paired constructs, namely: care/harm, fairness/cheating, loyalty/betrayal, authority/subversion and sanctity/degradation. Each of these foundations, it is argued, has resulted from a response to adaptive social pressures such as child care, partnerships and coalitions, hierarchical relationships and disease avoidance. ${ }^{21}$

Already MFT (or similarly-based approaches) have been applied to political contexts ${ }^{22}$ and such studies provide a model for the kinds of testable hypotheses and relevant data types. The possible application of MFT to PMCT and its communities could be manifold, including using it as a lens to examine tribal identity and policing of in- and out-group authoritarianism, and displays of moral sanctity.

Aside from the moral foundations themselves, one of the assumptions underpinning MFT is that (moral) intuitions come first in our reasoning, while the more effortful deliberative reasoning follows. This "intuitionism" model of Graham et al. (2003: 11) proposes that "moral evaluations generally occur rapidly and automatically" and that the more considered

\footnotetext{
${ }^{20}$ Graham, et al. 2013: 9.

${ }^{21}$ Graham et al. 2013: 58.

${ }^{22}$ For example, Stenner and Haidt, 2018: 175-220.
} 
and mental work that might follow is often used to justify the initial reaction. Moreover, this more considered moral reasoning is done primarily for socially strategic purposes rather than to "discover the honest truth." ${ }^{23}$ This cognitive predilection might align in interesting and dynamic ways with the similar predication for "patternicity" described earlier when considering PMCT. Type / errors could be driven by strong moral intuitions based on foundations such as those listed above. The positive feedback loop will be unchecked by rigorous tests, combined with strong in- and out-group signalling. Moreover, there is a pretence of effortful deliberative reasoning that supports the initial error, typically manifest as the almost indecipherable theoretical tracts of many PMCT texts.

Graham et al. (2003) enthusiastically call for the testing of their theory, as well as encouraging its application to new areas. I believe PMCT is one such area that would yield interesting results that could make for dynamic and stimulating responses in the academy, social media and in public policy.

\section{Conclusions and What Next?}

The overview above is speculative. What is required to progress any of the ideas touched upon are hypothesis-driven research programmes to test their viability and seek other ways of describing and understanding PMCT. Perhaps it is time to operationalise the ideas put forth via establishing a programme of evolutionary studies of postmodernism (ESPM).

What might ESPM look like? It would require a multidisciplinary team who can bring cognate approaches from evolutionary perspectives and a shared understanding of what constitutes the proper object of inquiry, study design and relevant evidence. In order to crystallize focus upon the institutional context of the academy, evolutionary-science literate scholars from the social sciences could bring a much-needed granularity to the specific topics and possible sources of evidence. Anthropologists and specialists in the study of belief systems (CSR) and pseudoscience communities would offer possible models for interdisciplinary research. Access to the PMCT community, by way of observation and detailed data, would be essential if the programme was to test hypotheses. Providing ESPM researchers access to nodes of PMCT activity, such as academic departments, research programmes, conferences, formal and informal university meetings and the like, would provide rich data and opportunities for hypothesis testing in the real world.

Such observation of behaviours could highlight any signalling and co-operative behaviours, the dynamics of in- and out-group delineation, and suggests how cognitive epistemological compartmentalism is maintained. Outside of such observational approaches, using a memetic approach would allow for the mapping of how ideas generated or reinforced in such institutional academic contexts to reach wider social-cultural environments and

\footnotetext{
${ }^{23}$ Graham et al. 2013: 11.
} 
spheres of influence. A Moral Foundation Theory-approach could also look at how wider societal group delineation and group identity operates, especially via social media and academic staff profile pages, for example.

There are wider aspects to the flourishing of PMCT within the academy that we might problematize within a broader Darwinian approach: what are the incentives for doing PMCT-driven research in the peculiar environment of the academy?; what academic and/or social rewards follow?; how have PMCT programmes flourished, being supported, developed their own power structures and incentives? What, in other words, is the political economy of PMCT, and what are the best tools to reveal it?

Finally, it is possible that even if the cultural units of information contained and propagated via PMCT might be untrue they might yet still serve important adaptive processes and so persist with long-term positive effects for groups (some kind of justifiable "means-vs-ends" proposition). It is also possible that PMCT is both untrue and risks serious social maladaptive consequences in its wake. While natural selection would predict that the latter scenario will result in the weeding out of the meme (or memeplex) in the long-run through the negative impact and decline of fitness in their hosts, I wonder if we are comfortable with simply letting nature take its course on this one.

\section{Further Reading}

Baehr, P. 2019. The Unmasking Style in Social Theory. New York: Routledge.

Barkow, J., Cosmides L, \& Tooby J. (eds.) 1992. The Adapted Mind: Evolutionary Psychology and the Generation of Culture. New York: Oxford University Press.

Barrett, J.L. 2013. “Cognitive Science of Religion." Pp.409-414 in Encyclopedia of Sciences and Religions, Runehov, A.L., Oviedo, L. and Azari, N.P. eds. Springer Netherlands.

Boudry, M. \& Braeckman, J. 2012. "How Convenient! The Epistemic Rationale of SelfValidating Belief Systems." Philosophical Psychology, 25(3), 341-364.

Boudry, M. \& Hofhuis, S. 2018. "Parasites of the Mind. Why Cultural Theorists Need the Meme's Eye View." Cognitive Systems Research, 52, 155-167.

Bulbulia, J. 2008. "Meme Infection or Religious Niche Construction? An Adaptationist Alternative to the Cultural Maladaptationist Hypothesis." Method \& Theory in the Study of Religion, 20(1), 67-107.

Bulbulia, J. \& Sosis, R. 2011. "Signalling Theory and the Evolution of Religious Cooperation." Religion, 41(3), 363-388.

Finkelstein, R. 2008. A Memetics Compendium, "Introduction." Defense Advanced Research Projects Agency. University of Maryland University College.

Cosmides, L., Tooby, J. \& Barkow, J.H., 1992. "Introduction: Evolutionary Psychology and Conceptual Integration." Pp 3-15 in The Adapted Mind: Evolutionary Psychology and the Generation of Culture, J. Barkow, L. Cosmides \& J. Tooby eds. New York: Oxford University Press.

Dawkins, R. 19762006 (1976). The Selfish Gene [30 ${ }^{\text {th }}$ Anniversary Edition]. Oxford: Oxford University Press. 
Graham, J., Haidt, J., Koleva, S., Motyl, M., Iyer, R., Wojcik, S.P. \& Ditto, P.H. 2013. "Moral Foundations Theory: The Pragmatic Validity of Moral Pluralism." Advances in Experimental Social Psychology. 47, 55-130.

Gross, P.R. \& Levitt, N. 1997. Higher Superstition: The Academic Left and its Quarrels with Science. John Hopkins University Press.

Hacking, I. \& Hacking, J. 1999. The Social Construction of What? Harvard University Press.

Haidt, J. 2012. The Righteous Mind: Why Good People are Divided by Politics and Religion. Vintage.

Heylighen, F. and Chielens, K. 2009. "Evolution of Culture, Memetics." Encyclopedia of complexity and systems science. 3205-3220.

Kitcher, P. 1998. "A Plea for Science Studies." Pp. 32-56 in A House Built on Sand: Exposing Postmodernist Myths about Science. Noretta Koertge ed. New York: Oxford University Press.

Koertge, N. (ed.) 1998. A House Built on Sand: Exposing Postmodernist Myths about Science. New York: Oxford University Press.

Lahti, D.C. \& Weinstein, B.S. 2005. "The Better Angels of Our Nature: Group Stability and the Evolution of Moral Tension." Evolution and Human Behavior. 26(1), 47-63.

McKay, R.T. \& Dennett, D.C. 2009. "The Evolution of Misbelief." Behavioral and Brain Sciences. 32(6), 493-510.

Pluckrose H. \& Lindsay J. 2020. Cynical Theories: How Activist Scholarship Has Made Everything About Race, Gender, and Identity - And Why This Harms Everybody. USA: Pitchstone.

Shaver, J.H. and Bulbulia, J.A., 2016. "Signaling Theory and Religion." Pp.101-117 in Religion: Mental Religion, Niki Clements ed. Farmington Hills, MI: Macmillan.

Shermer, M. 2011. The Believing Brain: From Ghosts and Gods to Politics and Conspiracies How We Construct Beliefs and Reinforce Them as Truths. New York: Macmillan.

Slingerland, E. 2008. What Science Offers the Humanities: Integrating Body and Culture. Cambridge: Cambridge University Press.

Sokal, A. 2010. Beyond the Hoax: Science, Philosophy and Culture. Oxford: Oxford University Press.

Sokal, A. \& Bricmont, J. 1998. Intellectual Impostures: Postmodern Philosophers' Abuse of Science. London: Profile Books.

Stenner, K. \& Haidt, J. 2018. "Authoritarianism is not a Momentary Madness, but an Eternal Dynamic within Liberal Democracies." Pp. 175-220 in Can it Happen Here?:

Authoritarianism in America. Cass Sunstein ed. New York: HarperCollins.

Wood, C. 2018. "Why Postmodernism and Science Can't Stand Each Other", November 29 2018, patheos.com accessed 15 January 2020. 